\title{
Das war der Intensivkurs Muskuloskelettale Radiologie 2021
}

Der Intensivkurs Muskuloskelettale Radiologie (IMR) fand - pandemiebedingt - auch in diesem Jahr als kompakte Online-Veranstaltung statt. Für die fünf Highlight-Sessions mit hochkarätigen Referenten hatten sich am 11. September 220 Teilnehmerinnen und Teilnehmer angemeldet.

Schwerpunktthemen des IMR-Kurses waren Oberes Sprunggelenk und Fuß sowie Muskel. Unter der wissenschaftlichen Leitung von Prof. Dr. Marc Regier gaben renommierte Experten ihr langjähriges Wissen aus Therapie und Diagnostik in spannenden Vorträgen an das Fachpublikum weiter.

Sollten Sie die Vorträge des Intensivkurses Muskuloskelettale Radiologie verpasst haben, können Sie sich diese noch bis Ende Juli 2022 auf conrad, der interaktiven Lernplattform der DRG, anschauen. Voraussetzung dafür ist, dass sie Teilnehmerin beziehungsweise Teilnehmer des IMR 2021 waren und Mitglied der Deutschen Röntgengesellschaft sind.

\section{IMR 2022}

Wir hoffen, Sie am 9. bis 10. September 2022 wieder wie gewohnt in der Bucerius Law School in Hamburg begrüßen zu können.

\section{Wissenschaftliche Leitung: Prof. Dr. Marc Regier}

